\section{Expanding team to meet digital dentistry demand}

Growing interest in digital technology from dental professionals in the UK and Ireland has led to the expansion of the team at The Dental Imaging Company - a leading independent specialist in X-ray, cone beam $\mathrm{CT}$ and surgical navigation systems.

Building on the company's reputation for technical expertise and practical support for its customers, the latest appointments bring a wealth of knowledge of dentistry and radiology.

Chris Meldrum, General Manager, has more than 35 years' experience in the dental industry, most notably in the field of dental implantology. Meldrum said: 'This is a great time to be joining the company. It's going from strength to strength, providing state-of-the-art technology to dental professionals, along with the support to ensure that customers can make the most of their investment. It is an exciting time to be involved in digital dentistry.'

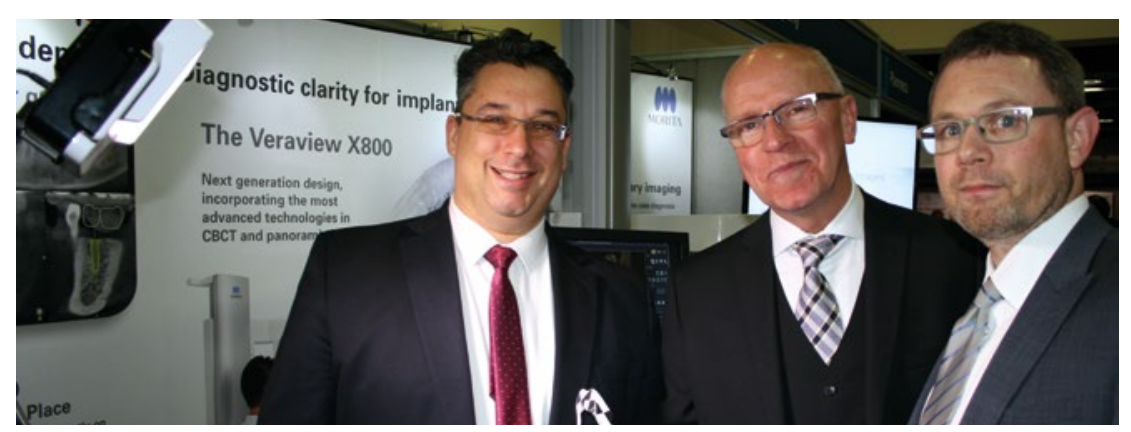

Rob Pounds (left) welcomes Chris Meldrum General Manager (centre), and Sean Goldner, Digital Sales Specialist (right), to the expanding team
Sean Goldner joins the team as Digital Sales Specialist. He has a thorough, practical understanding of CBCT and implant planning technology, having produced pre-surgical plans for clinicians across the UK for more than 15 years.

Goldner said: 'Dentists are keen to offer their patients outstanding clinical results and, in doing so, enhance their professional reputations. I am looking forward to demonstrating how Navident dynamic navigation and Morita scanners can help achieve these outcomes safely and predictably'

Rob Pounds, Managing Director, added: 'Having Chris and Sean on the team is great news for our customers, who will enjoy the benefits of their considerable experience. We are also expanding our engineering support provision, to help service the increased demand for digital technology in dentistry?.

For more information email dbaker@ cpac.com.

\title{
Excellent endodontic referrals
}

Advances in endodontics are resulting in higher rates of success than ever before - even for some teeth previously considered untreatable. ${ }^{1}$

BPI Dental has both the means and the experience to diagnose and treat patients suitable for endodontic care, including complex cases that would have once been considered too far gone for treatment.
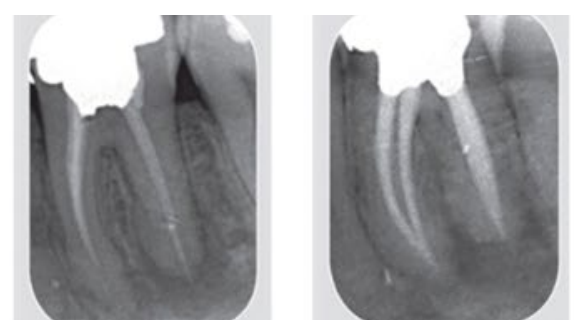

Don't let your patients miss out on a last chance to save their natural teeth. Contact BPI Dental's team of registered endodontic specialists to find out more about our referral service and how the company can help you help your patients.

For more information on the referral service available from Birmingham Periodontal \&
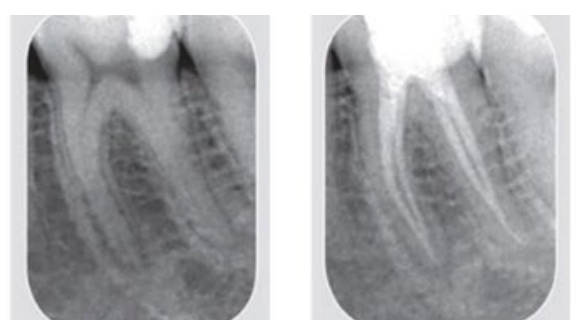

\section{Improving gingival health}

Patients with swollen gums, lesions or gingival enlargement can have difficulty achieving adequate oral hygiene, so Waterpik is recommending the Waterpik Water Flosser to help them maintain effective plaque control and improve gingival health.

As an adjunct to tooth brushing, the Waterpik Water Flosser is significantly more effective than string floss for removing plaque and reducing gingivitis.

The Flosser has also been shown to reduce pro-inflammatory mediators, bleeding on probing and probing pocket depths when compared to traditional oral hygiene measures.

More information on Waterpik is available by visiting www.waterpik. co.uk and its products are available from Amazon, Costco UK, Boots.com and Superdrug stores across the UK and Ireland.

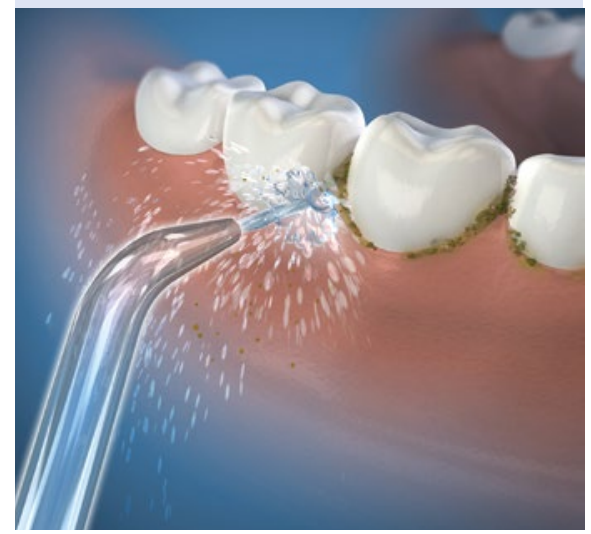

Implant (BPI) Dental, visit www.bpidental.co.uk, call 01214273210 or email info@bpidental.co.uk.

\section{References}

1. Kohli M, Berenji H, Setzer F, Lee S, and Karabucak B. Outcome of endodontic surgery: a meta-analysis of the literature - part 3: comparison of endodontic microsurgical techniques with 2 different root-end filling materials. J Endod 2018; 44: 923-931.
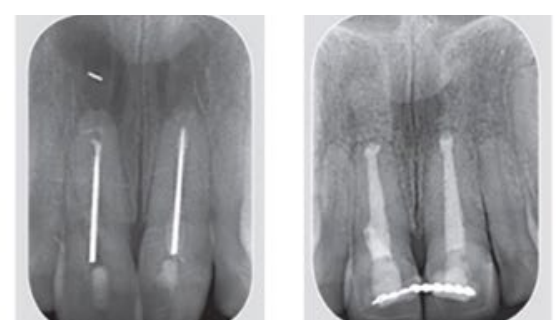